\title{
The Utility of the Metacognitive Awareness Inventory for Teachers among In-Service Teachers
}

\author{
Heli Kallio ${ }^{1}$, Kalle Virta ${ }^{1}$, Manne Kallio ${ }^{2}$, Arja Virta ${ }^{1}$, Finn Rudolf Hjardemaal $^{3}$ \& Jostein Sandven ${ }^{3}$ \\ ${ }^{1}$ Faculty of Education, University of Turku, Rauma, Finland \\ ${ }^{2}$ Faculty of Educational Sciences, University of Helsinki, Helsinki, Finland \\ ${ }^{3}$ University of South-East, Norway \\ Correspondence: Heli Kallio, Faculty of Education, University of Turku, Seminaarinakatu 1, 26100, Rauma, \\ Finland. E-mail: heli.kallio@utu.fi
}

Received: April 2, 2017

Accepted: April 30, $2017 \quad$ Online Published: June 5, 2017

doi:10.5539/jel.v6n4p78

URL: http://doi.org/10.5539/jel.v6n4p78

\begin{abstract}
The purpose of the present study is to explore the utility of the compressed version of the Metacognitive Awareness Inventory for Teachers (MAIT-18) among in-service teachers. Knowledge of teachers' awareness of metacognition is required to support students' self-regulation, with the aim of establishing modern learning methods and life-long learning. The participants in this study were teachers $(\mathrm{N}=208)$ from different sectors of vocational education. The data has been analysed using structural equation modelling. The Confirmatory Factor Analysis indicated good/acceptable model fit and convergence of each factor. Moreover, alpha scores of the inventory signify that the inventory is internally consistent. These findings reveal the utility of the MAIT-18 in measuring the Metacognitive Awareness of in-service teachers. Now, that the utility of the inventory has been examined among in-service teachers, comparative studies between in-service teachers and teacher trainees as well as longitudinal studies are prospective.
\end{abstract}

Keywords: Confirmatory Factor Analysis, in-service teachers, Metacognitive Awareness, the MAIT, vocational education

\section{Introduction}

The purpose of the present study is to examine the Metacognitive Awareness Inventory for Teachers, MAIT (Balcikanli, 2011) among in-service teachers. In previous studies, Teachers' Metacognitive Awareness is explored with inventories to a limited extend. For example the MAIT has been used in assessing student teachers, only. In the present study, the utility of the inventory was examined by calculating internal consistency and the fit of the factor structure, mentioned first related to reliability and the latter one points to validity of the instrument. Moreover, the utility of the instrument was improved by compressing the original 24-item version into 18-item version (MAIT-18).

The inventory was translated with the aim of studying the Metacognitive Awareness of teachers in vocational education in Finland. Currently, the topic is of high interest, since the secondary education, which vocational education belongs to, is under re-organisation. Authorisation to provide education will be re-considered by the Ministry of Culture and Education. The aim of Vocational Education and Training (VET) is to improve the skills of the work force, to respond to skills needs in the world of work and to support lifelong learning (Ministry of Education and Culture Finland, 2015). To gain these goals, it requires students' Self-Regulative Learning (SRL) skills and teachers' Metacognitive Awareness to support their students in the demanding processes of growth. At the same time, funding will be reduced and education providers are directed to improve their administration and learning culture. This might lead to a reduction in lessons, less traditional contact teaching, and more responsibility being placed on students with the application of modern teaching methods and learning styles. For students, this is a new opportunity to develop their Metacognitive Regulation and the associated abilities. These are skills, moreover, that are required both in work and lifelong learning. For teachers, this means a more supportive role in more learner-centred educational culture, which requires SRL skills from students.

To achieve good learning outcomes, students should be able to regulate their learning within different subject areas. This kind of setting requires a revision of the teachers' role. The teacher should be able to support students 
to improve their learning. Metacognition plays crucial role in all phases of learning (Livingston, 1997; Virta, 2005). For example, Vosniadou (1994) found that metacognition is an important factor in learning new concepts and transforming old ones. Metacognition is also an important factor in the regulation of one's own observations, memorising, and use of language processes (Metcalfe \& Shimamura, 1994). Furthermore, it is an important part of problem solving by experts in learning to learn (von Wright, 1996a, 1996b). Since teachers' Metacognitive Awareness in vocational education is still an area of research that has been studied to a small extent, it is highly important to develop the scientific discussion on the field. To gain information from the research area, the utility of the measuring methods needs to be explored.

The aim of this study is to point out the utility of the Metacognitive Awareness Inventory for Teachers. The research question is: What is the utility of the MAIT-18 among in-service teachers?

\section{Metacognitive Awareness, the Issues of Assessment and the Metacognitive Awareness Inventory for Teachers}

\subsection{Metacognitive Awareness}

Metacognition refers to the ability to understand one's learning. Metacognitive awareness is an important element in learning and crucial to the development of learner autonomy (Wenden, 1991; Wilkins, 1996). Marton and Booth (1997) describe the term "awareness" as a phenomenon, which manifests itself in variations the ways in which people experience situations and phenomena in their lives and worlds. According to Schraw and Dennisson (1994, p. 460) Metacognitive Awareness enables person to plan, sequence and monitor his or her learning so that the improvements can be seen directly in performances. Therefore, the Metacognitive Awareness is one of the key elements needed in developing autonomy in learning and teaching (see Balcikanli, 2011, p. 1319). In this study the concept of awareness is described as a personal understanding and specifying conscious thinking of one's own teaching.

Metacognition is generally defined as the activity of monitoring and controlling one's cognition (Ormrod, 2004; Young \& Fry, 2008). There are a lot of literature reviews from Flavell (1976) and Brown (1978) until the later researches (e.g., Martinez \& Davalos, 2016; Balcikanli, 2011; Hacker, Dunlosky, \& Graesser, 2009; Dinsmore, Alexander, \& Loughlin, 2008; Lai, 2011; Whitebread et al., 2009; Thompson \& Johnson, 2014) that studies on metacognition. Flavell (1976, p. 232) first defined metacognition as the knowledge of one's own cognitive processes. However, there is no general unanimity of the definition of metacognition yet. A distinction is generally made between Metacognitive Knowledge and Metacognitive Regulation (Brown, 1987; Schraw \& Moshman, 1995; Schraw \& Dennison, 1994; Young \& Fry, 2008). This two-component model of metacognition, Knowledge of Cognition (i.e., Metacognitive Knowledge) and Regulation of Cognition (i.e., Metacognitive Regulation), has received approval from researchers and it has been widely used.

Metacognitive Knowledge seems to involve reflective understanding of the process under consideration and of the actor's role in it (von Wright, 1992). Flavell (1977) divides Metacognitive Knowledge into three categories: knowledge of personal variables, task variables, and strategy variables (see also Brown, Bransford, Ferrara, \& Campione, 1983; Bråten, 1991a; Livingston, 1997). The widely used theory of Metacognitive Knowledge (Brown, 1978; Brown, 1987; Schraw \& Moshman, 1995; Schraw \& Dennison, 1994; Jacobs \& Paris, 1997; Young \& Fry, 2008) contains three kind of knowledge: declarative, procedural, and Conditional Knowledge. Schraw and Moshman (1995, p. 352) describes Declarative Knowledge to be "knowing about things", procedural "to know how to do things" and conditional "to know why and when to do things". Such Metacognitive Regulation refers to the steps that a person take to regulate and modify the progress of the cognitive activity, for example, the flexible employment of different processing activities, depending on circumstances and on interim learning outcomes. The Metacognitive Regulation activities are: orienting/planning before a certain course or assignment, monitoring/testing/diagnosing and adjusting during a learning task or a course, and evaluating/reflecting on one's own learning at the end of the learning task or a course (Vermunt \& Verloop, 1999). Even though a number of Metacognitive Regulation skills have been described in the literature, there are three components mentioned repeatedly: planning, monitoring, and evaluation (Jacobs \& Paris, 1978; Schraw \& Dennisson, 1994).

The concept of metacognition would be incomplete without consideration of Self-Regulated Learning (SRL) since the literature often discusses them concurrently (Hacker, Dunlosky, \& Graesser, 2009; Schraw, Crippen, \& Hartley, 2006; Zimmerman \& Schunk, 2011). Self-Regulated Learning Theory (SRLT) describes the relationship between cognition and metacognition (Schraw \& Dennison, 1994). One of the primary goals of education is to foster learners' SRL (Greene, Costa, \& Dellinger, 2011). There are many models of SRL (e.g., Pintrich, 2000; Winne \& Hadwin, 2008; Zimmerman, 2000; see also Greene, Costa, \& Dellinger, 2011; Virta, 2005). Bandura 
(1977) defined self-regulation as the ability to control our own behaviour. According to Zimmerman (1989) all models of SRL assume that learners are aware of the potential usefulness of these self-regulatory processes in enhancing their cognitive performance (see also Bråten, 1991b). Schoenfeld (1987) includes self-regulation as a component of metacognition. The terms Metacognitive Regulation of learning and self-regulation of learning have the same kind of content (Vermunt \& Verloop, 1999).

According to studies concerning the support needed for students practicing SRL, instructional strategies can improve metacognitive skills (Brandsford, Brown, \& Cocking, 2000; Tanner, 2012). Therefore, in order to improve learning results, the support given by teachers in SRL to students must be considered one of the main tasks for teachers. However, teachers also need to know their own abilities in this area first in order to be able to help their students to learn to improve their skills in SRL. Teachers should understand the principles about how students learn (Brookhart, 2011, p. 4) and they should be aware of their own metacognitive abilities. The instrument used in this study was designed to confirm the theoretical existence of the two-component model of metacognition (Brown, 1987; Schraw \& Dennisson, 1994); Knowledge of Cognition and Regulation of Cognition.

Metacognition does not only work for the students but it helps the teachers to improve their teaching skills. There are several studies and inventories focused on students' metacognition, but only few taking account to teachers' Metacognitive Awareness or even less studies where in-service teachers were examined. It is highly important for teachers themselves to be able to see their own level of awareness in Metacognitive Knowledge and regulation.

\subsection{Issues of Assessment}

One way to assess Metacognitive Awareness is to ask a person to complete a self-report questionnaire. To study Metacognitive Awareness, there are several inventories, that are used for that purpose (Favieri, 2013; Biggs, 1987; Entwistle \& Ramsden, 1983; Angelo \& Cross, 1993; Weinstein, Zimmerman, \& Palmer, 1988; Pintrich, Smith, Garcia, \& McKeachie, 1991; Zimmerman \& Martinez-Pons, 1986; Boulton-Lewis, Wilss, \& Mutch, 1996). In all these studies the character of the information has been studied from the pupil's point of view. Schraw and Dennison (1994) developed the Metacognitive Awareness Inventory (MAI) for students that was used as a basis of the Metacognitive Awareness Inventory for Teachers (MAIT) (Balcikanli, 2011). Chan (2001) developed the assessment inventory the Conception of Teaching and Learning Questionnaire (CTQL). However, according to Teo and Sing (2008, p. 216) who explored the CFA of the questionnaire, the beliefs and ideas of teaching and learning are often culture specific. CTLQ has been developed to serve the developing of the school and teaching especially in the Asian countries and is therefore weakly suitable for to be used in examining the Western countries' teaching culture. Also, a six-factor structure scale, Teacher Metacognition Inventory (TMI) developed by Jiang, Ma and Gao (2016), was validated during a teacher training program in China.

The validity of self-report questionnaires have been criticised by some scholars for not assessing metacognition and self-regulation widely enough (Schellings, van Hout-Wolters, Veenman, \& Meijer, 2013). Winne and Jamieson-Noel (2002) noted that the report itself does not necessarily specify exactly what students are doing while they are studying. Virta (2005) found that for example in self-direction the self-report questionnaire points out the readiness of the students but not necessarily the ability. Knowing the limitations is crucial. According to Kuhn (1989) it may be difficult to engage in scientific reasoning when one is not understanding the theory in it. However, a validated and structured questionnaire has its benefits. One of the reasons why a questionnaire may help a person to construct a picture of ones' cognition, are ready claims to answer, based on the theory beyond the assessing tool. Hence, it may help a person to understand theoretically the phenomena that is assessed (Schraw \& Moshman, 1995, p. 367) and thereby help a person to evaluate his/her regulation in teaching or learning. In this study, the awareness in metacognition and the readiness in Self-Regulation (SR) is studied, not the metacognition or SR itself. In some scholars, the term "perceived self-regulation" is used when assessing the awareness or readiness of metacognition and self-regulation. Perceived self-regulation is also a term used when measuring self-regulation by using self-report questionnaires and collecting data with these inventories (Helle, Laakkonen, Tuijula, \& Vermunt, 2013; Bandura, 1988b).

Examining the utility of an inventory concerns the validity of it, as well. However, the definition of the validation is a complex one as the reviewers have separate views of it (e.g., Goldstein, 2013; Mc Grath, 2005; Barret, 1992). According to Geisinger (2016, p. 287) the processes in validation should meet certain factors. Results following the measuring should be duly used for certain purposes of use and also the same the results would have to be reasonably interpreted. Since the concept of the validation itself is complex, Geisinger recommends to use the term utility instead of the term validity. Berger and Karabenick (2016) underline the 
opportunities of self-report instruments of large-scale testing and the practical advantages. Every method has its own quality but the further examination is needed for to develop more exact measures. The present study takes the position that research is best served by improvements in their reliability and validity. This kind of study could not only have the purpose of improving the self-report itself but also building the advantages of measuring Metacognitive Awareness.

\subsection{The Metacognitive Awareness Inventory for Teachers}

There are several studies and inventories focused on students' metacognition, but only a few take into account the teachers' Metacognitive Awareness, and there are even less studies where both of these groups are examined. From all the inventories measuring the Metacognitive Awareness in teaching and studying the Metacognitive Awareness Inventory for Teachers was chosen as the most suitable for this study. First of all, because it is constructed on the same components as a students' version, the Metacognitive Awareness Inventory (MAI), is based on. Later on, during this research project, these two inventories will be used simultaneously to explore the interconnection between teachers and students. To support students' self-regulation teachers should be able to regulate their own actions, i.e., teaching. It is highly important for teachers themselves to be able to see their own level of awareness in Metacognitive Knowledge and regulation. In order to be able to teach the Metacognitive Knowledge and regulation suitable for their students, teachers should be aware of those on their own level first.

The Metacognitive Awareness Inventory for Teachers (Balcikanli, 2011) is based on Self-Regulated Learning theory and it is derived from the Metacognitive Awareness Inventory for Adults (MAI) (Schraw \& Denisson, 1994). It is strongly believed that knowing what teachers know about their teaching should be a changing point for teachers' development. The MAIT-inventory is considered to be a resource that helps teachers realize their metacognitive levels of teaching (Balcikanli, 2011, p. 1320). Based on the inventory, the respondents, who were student teachers of English Language Teaching, awareness was measured in both components, based on the Brown (1987) two-component model of metacognition, Knowledge of Cognition and Regulation of Cognition. Each of the components was made up of other sub components. The questionnaire was modified to a 5 point Likert-Scale with a range from (1) "strongly disagree" to (5) "strongly agree". The intention of the 24-item questionnaire was to confirm the theoretical existence of eight subcomponents of metacognition: Declarative Knowledge, Procedural Knowledge, Conditional Knowledge, Planning, Information Management Strategies, Monitoring, Debugging Strategies, and Evaluation of Learning. The final factor loading was based on six factors including Declarative, Procedural, and Conditional Knowledge in Knowledge of Cognition, and activities such as Planning, Monitoring, and Evaluation in Regulation of Cognition. Lastly, the 4 items in the six subcomponents of cognition was sum up to 24 items that were designed for the inventory. As the Cronbach's Alpha varied from .79 to .85 , this signifies that the inventory denoted high alpha scores.

Seraphin, Philippoff, Kaupp and Vallin (2012) studied the impact of professional development on the metacognition and learning in science education. They modified a selection of the Metacognition Awareness Inventory (MAI) (Schraw \& Dennison, 1994) using questionnaires for both teachers and students. In addition, teachers were asked to respond to ten statements from the MAIT. The results of the analysis suggested that the ability to evaluate cognitive strengths and weaknesses is possible among teachers and students and they can learn to use that knowledge strategically. Both novice and experienced teachers benefited from a metacognition-focused scientific inquiry in their professional development. The results also suggest that teachers need to be supported in their metacognitive development (Seraphin et al., 2012, p. 378). Ghonsooly, Khajavy and Mahjoobi (2014) used the MAIT and Teachers' Sense of Self-Efficacy Scale (TSES) (Woolfolk \& Hoy, 1990) in their study to investigate the predictability of the teacher trainees' academic achievement based on their scores in self-efficacy and metacognition. Furthermore, the difference between the self-efficacy and metacognition of males and females was investigated. The results of the Path Analysis indicated that both metacognition and self-efficacy have an influence on academic performance, with metacognition having the stronger effect. Moreover, no differences between male and female self-efficacy and metacognition were found per the results of the t-test. In Malaysia, a sample of 52 science teachers were asked to answer the MAIT. The results of this study disclosed that science teachers have a high level of perception about metacognition. No significant differences have been found in Malaysia related to teachers' gender or age, although an interaction between teachers' age and educational level was predictable (Mai, 2015, p. 88). 


\section{Method}

\subsection{Participants}

The participants in this study were teachers $(\mathrm{N}=208)$ from three training consortiums providing vocational education. The training consortiums, committed to the research project, consisted of 13 units, altogether, approximately 450 teachers, while the student count for each unit was between 350 to 600 students.

In Finland, vocational education is a part of secondary education after basic education as post-compulsory education system, which is divided into two levels: vocational education and general upper secondary school. The largest sectors of vocational education are technology and transport, business and administration and health and social services, tourism, catering and home economics, and culture. The Ministry of Education and Culture has confirmed 119 different study programmes leading to 53 vocational qualifications to respond to labour market needs. The qualification is 120 credits, which takes three years of full-time study, unless prior learning can be counted towards the qualification. Vocational education teachers in Finland are generally highly valued and respected. The training requirements for vocational education teachers are fairly broad. Firstly, teachers of vocational subjects must have an appropriate master's or bachelor's degree in their own vocational sector. If such a degree does not exist, it can also be supplemented by the highest possible other qualification in the sector. Secondly, they have a pedagogical teacher training with the scope of 60 ECTS credit points, and thirdly they need relevant work experience in their own field (Ministry of Education and Culture Finland, 2015).

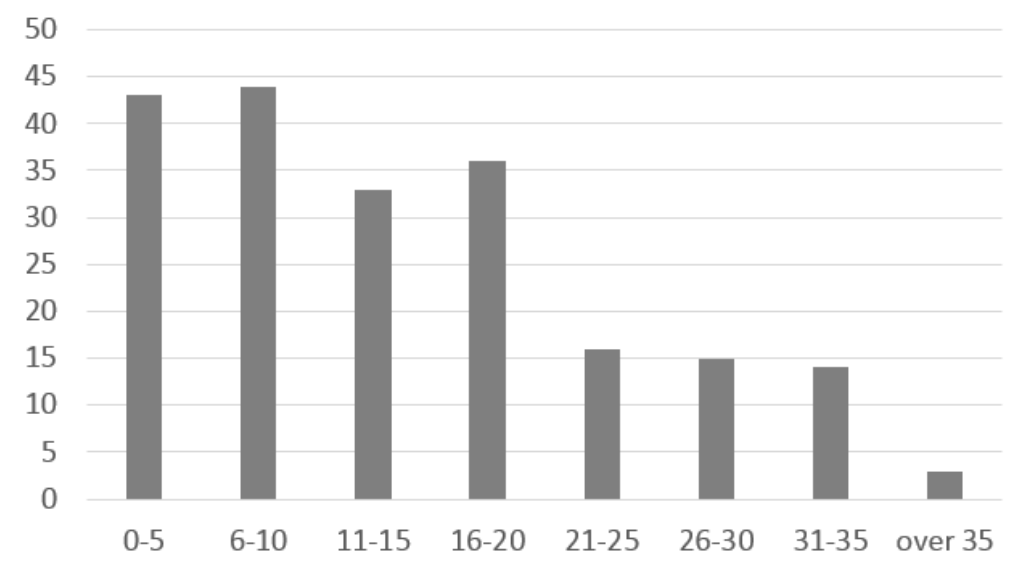

Figure 1. Participants' in-service teacher experience in years

Participants' in-service experience varied so that as well novices and well-experienced teachers were present in the data (in-service experience: mean $=14.8$, median $=13$ ). Forty-seven percent of the participants were men $(\mathrm{n}$ $=98)$ and fifty-three percent were women $(\mathrm{n}=110)$. The participants in the study were teachers from different sectors of vocational education, such as business economics, social and health, tourism and catering, transport and logistics, vehicle, electricity, culture, education, the construction branch, beauty treatment, ICT, the engineering and metal industry, seafaring, audiovisual communication, and the visual arts. The data was collected in 2015 and in the spring of 2016 under agreement with the boards of the participating training consortiums. All teachers participated in the study voluntarily.

\subsection{Measures}

Since the original Balcikanli's (2011) Metacognitive Awareness Inventory for Teachers (MAIT) is in English it was translated into Finnish for this research project using a three-step procedure. First, three researchers, all native Finnish speakers, made their own version of each item in the inventory and then the versions were combined. Furthermore, the items were checked by a Finnish mother tongue lecturer. In the second step, the new Finnish questionnaire was translated into English, again, by an experienced translator to ensure that the concepts and phrases are translatable both from English in Finnish and vice versa. The final version was the result of certain modifications and suggestions made by the translators and mother tongue lecturers. The third step of the procedure was to test the inventory questionnaire using a group of teachers $(n=8)$ in a secondary vocational institute. The teachers were presented with the research project similar to that used when the main data was 
collected later. Moreover, the pilot group was asked to pay special attention to possible unfamiliar concepts or unclear statements. When using a questionnaire as self-report instrument, one must study carefully what kind of implications or interpretations a person may have (Hopfenbeck, 2009, p. 17). The teachers were asked to present their questions or notes instantly or write them on the questionnaire form. There were no comments on the questionnaire when it was pre-tested by the teachers. The variables were measured on a five-point Likert scale. The respondents were asked to rate each item on a 1-to-5 response scale where the numbers presented following opinions: 1 "never"; 2 "seldom"; 3 "sometimes"; 4 "often" and 5 "always".

\subsection{Procedure of Analysis}

The analysis of the data took place in two steps following the research question: first the internal consistency and then the fit of factor structure of the inventory was explored. The consistency of the factor structure was explored using cross tabulation and calculating the Pearson's correlation between the items in each factor. Moreover, Cronbach's (1951) alphas were calculated for all factors. Then, the factor structure of the questionnaire was measured and tested using Confirmatory Factor Analysis (CFA). To compress the questionnaire into 18-item version, one item from each factor was removed during the procedure.

\section{Results}

\subsection{The First Step: Internal Consistency}

Exploring the descriptive statistics of the items and bivariate correlations between the items within each factor revealed how the measurement could be compressed (Table 1).

Table 1. Descriptive statistics and correlations of MAIT-24

\begin{tabular}{|c|c|c|c|c|c|c|c|c|}
\hline \multirow[b]{2}{*}{ Factor Item } & \multicolumn{4}{|c|}{ Descriptives } & \multicolumn{4}{|c|}{ Pearson's correlation } \\
\hline & M & SD & Kkewness & Kurtosis & & & & \\
\hline 1 Declarative Knowledge & & & & & 1 & 2 & 3 & 4 \\
\hline $\begin{array}{l}\text { I am aware of the strengths and weaknesses in my } \\
\text { teaching. }\end{array}$ & 4.15 & .64 & -.58 & 1.17 & & & & \\
\hline $\begin{array}{l}\text { I Know what skills are most important in order to be a good } \\
\text { teacher. }\end{array}$ & 3.69 & .82 & -.66 & .50 & .37 & & & \\
\hline 3 I have control over how well I teach. & 3.84 & .71 & -.24 & -.07 & .22 & .32 & & \\
\hline 4 I know what I am expected to teach. & 4.32 & .61 & -.43 & .07 & .33 & .40 & .25 & \\
\hline 2 Procedural Knowledge & & & & & 5 & 6 & 7 & 8 \\
\hline 5 I try to use teaching techniques that worked in the past. & 3.97 & .47 & -.94 & 5.10 & & & & \\
\hline $\begin{array}{l}\text { I have specific reason for choosing each teaching } \\
\text { technique I use in class. }\end{array}$ & 3.80 & .71 & -.74 & 1.28 & ns. & & & \\
\hline $\begin{array}{l}7 \text { I am aware of what teaching techniques I use while I am } \\
\text { teaching. }\end{array}$ & 4.06 & .78 & -1.13 & 2.27 & ns. & .51 & & \\
\hline 8 I use helpful teaching techniques automatically. & 3.60 & .58 & -.42 & -.18 & .29 & .32 & .29 & \\
\hline 3 Conditional Knowledge & & & & & 9 & 10 & 11 & 12 \\
\hline $\begin{array}{l}\text { I use my strengths to compensate for my weaknesses in my } \\
\text { teaching. }\end{array}$ & 3.69 & .72 & -.16 & -.17 & & & & \\
\hline 10 I can motivate myself to teach when I really need to teach. & 3.99 & .69 & -.43 & .89 & .22 & & & \\
\hline $\begin{array}{l}\text { I use different teaching techniques depending on the } \\
\text { situation. }\end{array}$ & 4.12 & .68 & -.61 & .80 & .36 & .28 & & \\
\hline
\end{tabular}




\begin{tabular}{|c|c|c|c|c|c|c|c|c|}
\hline $\begin{array}{l}12 \text { I know when each teaching technique I use will be most } \\
\text { effective. }\end{array}$ & 3.33 & .75 & -.37 & .00 & .24 & .32 & .36 & \\
\hline 4 Planning & & & & & 13 & 14 & 15 & 16 \\
\hline $\begin{array}{l}\text { I pace myself while I am teaching in order to have enough } \\
\text { time. }\end{array}$ & 3.88 & .85 & -.56 & .10 & & & & \\
\hline 14 I set my specific teaching goals before I start teaching. & 4.05 & .88 & -.90 & .55 & .33 & & & \\
\hline $\begin{array}{l}\text { I ask myself questions about the teaching materials I am } \\
\text { going to use. }\end{array}$ & 4.43 & .71 & -1.09 & .73 & .50 & .33 & & \\
\hline 16 I organize my time to best accomplish my teaching goals. & 3.93 & .91 & -.89 & .69 & .56 & .53 & .38 & \\
\hline 5 Monitoring & & & & & 17 & 18 & 19 & 20 \\
\hline $\begin{array}{l}\text { I ask myself periodically if I meet my teaching goals while } \\
\text { I am teaching. }\end{array}$ & 3.77 & .75 & -.54 & .63 & & & & \\
\hline $\begin{array}{l}\text { I find myself assessing how useful my teaching techniques } \\
\text { are while I am teaching. }\end{array}$ & 3.67 & .78 & -.32 & -.19 & .51 & & & \\
\hline $\begin{array}{l}19 \text { I check regularly to what extent my students comprehend } \\
\text { the topic while I am teaching. }\end{array}$ & 3.93 & .68 & -.38 & .39 & .44 & .39 & & \\
\hline $\begin{array}{l}\text { I ask myself questions about how well I am doing while I } \\
\text { am teaching. }\end{array}$ & 3.63 & .86 & -.56 & .08 & .39 & .44 & .36 & \\
\hline 6 Evaluating & & & & & 21 & 22 & 23 & 24 \\
\hline $\begin{array}{l}\text { I ask myself how well I have accomplished my teaching } \\
\text { goals once I am finished. }\end{array}$ & 3.84 & .85 & -.61 & .38 & & & & \\
\hline $\begin{array}{l}22 \text { ask myself if I could have used different techniques after } \\
\text { each teaching experience. }\end{array}$ & 3.50 & .81 & -.43 & .35 & .46 & & & \\
\hline $\begin{array}{l}23 \text { After teaching a point, I ask myself if I'd teach it more } \\
\text { effectively next time. }\end{array}$ & 3.89 & .71 & -.40 & .24 & .37 & .50 & & \\
\hline $\begin{array}{l}\text { I ask myself if I have considered all possible techniques } \\
\text { after teaching a point. }\end{array}$ & 3.63 & .81 & -.31 & -.05 & .49 & .60 & .45 & \\
\hline
\end{tabular}

PEARSON'S CORRELATIONS BETWEEN ITEMS WITHIN A FACTOR.

ns. $=$ NON-SIGNIFICANT CORRELATION $(\mathrm{p}>.05)$.

Item \#5 from the factor of Procedural Knowledge was removed since it had non-significant correlations with other items in their factors. Item \#3 from the factor of Declarative Knowledge was removed, since it was regarded as a difficult claim according to some participants. Also, terms concerning "effectiveness" in items \# 12 from the factor of Conditional Knowledge and \#23 from the factor of Evaluating were regarded as confusing concepts and therefore, since it was too difficult to response these claims for some participants, they were also removed. Moreover, the item \#15 from the factor Planning revealed too positive values for the skewness and was hence removed. Since the item \#20 "I ask myself questions about how well I am doing while I am teaching" was regarded somewhat an unclear claim by researchers, it was also considered to be an unsuitable claim to measure Monitoring. Since six items, one from each factor, were removed the new structure of MAIT-18 was completed.

The internal consistency was estimated by calculating Cronbach's (1951) alpha for the compressed questionnaire MAIT-18. According to Gliner, Morgan and Harmon (2001) the value of the alpha ought to be $>.60$. As the results of Cronbach's alphas were from $.80(95 \%$ C.I. $=.76-.84)$ in Knowledge of Cognition (Declarative Knowledge $\alpha=.63$, Procedural Knowledge $\alpha=.61$ and Conditional Knowledge $\alpha=.63)$ to $.86(95 \%$ C.I. $=.83-.89)$ in Regulation of Cognition (Planning $\alpha=.73$, Monitoring $\alpha=.71$ and Evaluating $\alpha=.76$ ), the internal consistency of all the factors was found good and, moreover, the alpha of the entire questionnaire was $.90(95 \%$ C.I. 
$=.88-.92)$. Moreover, the internal consistency was explored within participated training consortiums separately (Table 2).

Table 2. The internal consistency of the components (within Training Consortiums)

\begin{tabular}{cccc}
\hline \multirow{2}{*}{$\begin{array}{c}\text { Training } \\
\text { consortium }\end{array}$} & \multicolumn{3}{c}{ Cronbach's alphas } \\
\cline { 2 - 4 }$\# 1$ & Regulation of cognition & Knowledge of cognition & Entire questionnaire \\
\hline 2 & .88 & .86 & .92 \\
$\# 3$ & .87 & .83 & .91 \\
\hline
\end{tabular}

The analysis of the internal consistency of the components and entire questionnaire was found good and even excellent within the first two consortiums. The internal consistency of the Regulation of Cognition was better than in the Knowledge of Cognition. The analysis of the descriptive statistics and correlations (Appendix 1) and the internal consistency revealed that the data was suitable for the $2^{\text {nd }}$ step: exploring the factor structure of the MAIT-18 using the CFA.

\subsection{The Second Step: Confirmatory Factor Analysis and the Fit of the Factor Structure}

In the CFA method and in SEM, the fit of the factor structure can be verified with several indexes. The Chi Square $\left(\chi^{2}\right)$ describes the difference between the theoretical and measured covariance matrix. The interpretation of the $\chi^{2}$ value is ambiguous. Therefore, model fit needed to be assessed using several indexes (Hair, Black, Babin, \& Anderson, 2010; West, Taylor, \& Wu, 2012; Ullman, 2001; McDonald \& Ho, 2002). The Comparative Fit Index (CFI) and the Tucker-Lewis Indexes (TLI) compare model fit with the independence model. In this study, the cut-off value of good model fit for both CFI and TLI was .95 (Hu \& Bentler, 1999; Hoyle, 1995) and of acceptable model fit was 90 (Byrne, 2012; Hoe, 2008; Hoyle, 1995; McDonald \& Ho, 2002). The Root Mean Square Error of Approximation (RMSEA) indicates model fit in comparison with the degree of freedom of the model (Steiger, 1990). A cut-off value of .05 indicates good fit of the model and a cut-off value of .08 indicates acceptable fit of the model .08 (Byrne, 2012; Hoe, 2008; Steiger, 2000). Standardized Root Mean Square Residual (SRMR) indicates the model fit by comparing the averages of the standardised residuals of the observed and predicted covariance matrixes. A cut-off value of close to .08 indicates a good model fit (Hu \& Bentler, 1999). However, Hu and Bentler (1995) suggest cut-off value of .10 for acceptable fit.

The questionnaire consists of two patterns of factors revealing two underlying theoretical structures of metacognition. Both theories are operationalised in three factors. Subsequently, the factor patterns were analysed using Confirmatory Factor Analysis.
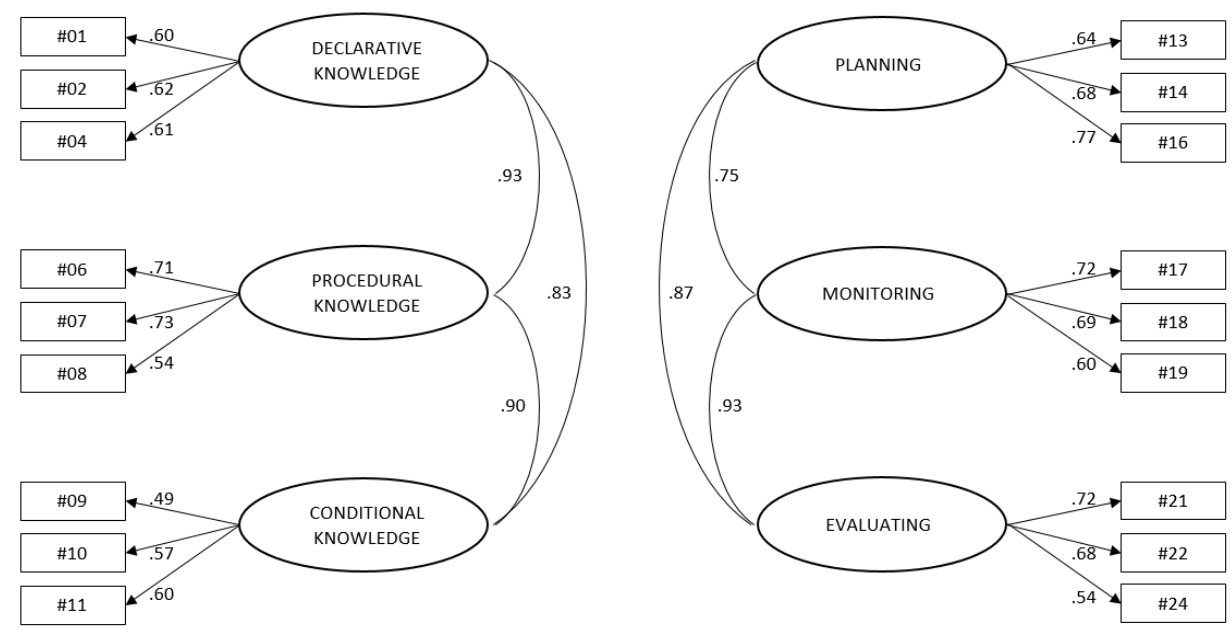

$\mathrm{X} / \mathrm{df}=1.73 ; \mathrm{RMSEA}=.06 ; \mathrm{CFI}=.92 ; \mathrm{TLI}=.90 ; \mathrm{SRMR}=.05$

Figure 2. The Confirmatory Factor Analysis of the factor patterns of the MAIT-18 
The instrument was designed to confirm the theoretical existence of the two-component model of metacognition (Brown, 1987; Schraw \& Dennisson, 1994), Knowledge of Cognition and Regulation of Cognition. Both components were comprised of three sub components including Declarative, Procedural, and Conditional Knowledge in Knowledge of Cognition and activities Such as Planning, Monitoring, and Evaluation in Regulation of Cognition. No cross-loadings were added into the model, however, the components are quite close to each other. The result of the final CFA of the MAIT-18 revealed a good/acceptable fit of the factor structure $\left(\chi^{2} / \mathrm{df}=1.73 ; \mathrm{RMSEA}=.06 ; \mathrm{CFI}=.92 ; \mathrm{TLI}=.90 ; \mathrm{SRMR}=.05\right)$.

When analysing the Knowledge of Cognition patterns and the Regulation of Cognition patterns separately, the CFA of the Knowledge patterns, i.e., the Declarative, Procedural and Conditional Knowledge respectively, revealed the good fit of the factor structure $\left(\chi^{2} / \mathrm{df}=2.20\right.$; RMSEA $=.07$; CFI $=.92$; TLI $=.88$; SRMR $\left.=.05\right)$. The result for the CFA of the patterns of Regulation (Planning, Monitoring and Evaluating, respectively) revealed a good/acceptable fit for the factor structure $\left(\chi^{2} / \mathrm{df}=1.46 ; \mathrm{RMSEA}=.05 ; \mathrm{CFI}=.98 ; \mathrm{TLI}=.97\right.$; SRMR $=.04)$. The results reveal that the fit of the factor structure of the entire questionnaire was good/acceptable within the separate groups of the participants, irrespective of sex, academic degree or the qualification details.

The Confirmatory Factor Analysis indicated convergence of each factor. Moreover, alpha scores of the inventory signify that the inventory is internally consistent. These findings reveal the utility of the MAIT-18 in measuring the Metacognitive Awareness of in-service teachers.

\section{Discussion}

The present study explored the utility of the 18-item version of the Metacognitive Awareness Inventory for Teachers (MAIT-18). This study points out the utility of the inventory in Finland in vocational education, particularly. Because the results show the solidness and convergence of the instrument, it can be expected to produce information concerning teachers' Metacognitive Awareness. Hence, the study creates a new use for the Metacognitive Awareness Inventory for Teachers in the area of vocational education which is rarely studied. The results revealed that the original instrument had some weaknesses, and therefore it was important to adjust the items of the instrument by compressing the entire MAIT-questionnaire and hence, to explore the fit of the factor structure. After compressing the number of items from 24 to 18 , the fit of the factor structure of the entire questionnaire was good/acceptable.

Teachers' Metacognitive Awareness is still an area of research which has been studied to a small extent, however, more research has been focused on students' Metacognitive Awareness (Schraw \& Denisson, 1994; Brandsford, Brown, \& Cocking, 2000; Tanner, 2012). One of the primary goals of education is to foster learners' SRL (Greene, Costa, \& Dellinger, 2011). To achieve this goal, more research focused on teachers' contribution is needed. Teachers benefit metacognition-focused scientific inquiry in their professional development, however, they also need to be supported in their metacognitive development (Seraphin et al., 2012). Metacognitive Awareness is a key for a teacher to reflect their own work and the support they give to their students in SRL skills, particularly. Since teachers' Metacognitive Awareness is still an area of research which has been studied to a small extent, it is highly important to gain more detailed empirical research in the field. The aim of this study, which was to explore the utility of the instrument concerning the Metacognitive Awareness for comparable data acquisition among in-service teachers was fulfilled.

The MAIT-18 will enable the use of large samples in comparable studies internationally in different cultures of learning and teaching. However, criterion validity should be estimated related to other scales, for example cognitive performance factors, simultaneously when assessing metacognitive awareness. The compressed versions of questionnaires are required, since the participants are able to concentrate only on certain amount of questions, in total. Since the three-item structure is optimal to gain the reliability requirements, the MAIT-18 is of high value for further analysis. The results of the comparative studies will be current and highly valued. The results of further studies applying MAIT-18 can be used in developing a teaching and learning culture in teacher training. Teachers need knowledge about the Metacognitive Awareness; how do they reflect themselves, where should they pay attention and what should they develop? Students need knowledge and skills of self-regulation when aiming for success in learning outcomes, further studies, and employment. However, teachers need to know their own abilities in this area, first, to be able to help their students to learn to improve their skills in SRL. Teacher education could be improved by focusing on monitoring and developing the trainees' readiness in Metacognitive Awareness and also, by promoting them in encouraging the self-regulation of learners. Teachers' support in SRL is a principal feature of lifelong learning. Now, that the utility of the Metacognitive Awareness Inventory for Teachers has been examined among in-service teachers, as well, comparative studies between in-service teachers and teacher trainees as well as longitudinal studies are prospective. 


\section{References}

Angelo, T. A., \& Cross, K. P. (1993). Classroom assessment techniques: A handbook for college teachers (2nd ed.). San Francisco: Jossey-Bass.

Balcikanli, C. (2011). Metacognitive Awareness inventory for teachers (MAIT). Electronic Journal of Research in Educational Psychology, 9(25), 1309-1332.

Bandura, A. (1977). Social learning theory. Englewood Cliffs, NJ: Prentice Hall Publishers.

Barrett, G. V. (1992). Clarifying construct validity: Definitions, processes, and models. Human Performance, 5(1-2), 13-58. https://doi.org/10.1080/08959285.1992.9667923

Berger, J. L., \& Karabenick, S. A. (2016). Construct Validity of Self-Reported Metacognitive Learning Strategies. Educational Assessment, 21(1), 19-33. https://doi.org/10.1080/10627197.2015.1127751

Biggs, J. (1987). Student approaches to learning and studying. Hawthorn, Victoria: ACER.

Boulton-Lewis, G. M., Wilss, L., \& Mutch, S. (1996). Teachers as adult learners: Their knowledge of their own learning and implications for teaching. Higher Education, 32, 89-106. https://doi.org/10.1007/BF00139220

Bransford, J. D., Brown, A., \& Cocking, R. (2000). How people learn: Mind, brain, experience and school, expanded edition. DC: National Academy Press, Washington.

Bråten, I. (1991a). Vygotsky as a precursor to metacognitive theory: I. The concept of metacognition and its roots. Scandinavian Journal of Educational Research, 35(3), 179-192. https://doi.org/10.1080/0031383910350302

Bråten, I. (1991b). Vygotsky as a precursor to metacognitive theory: II Vygotsky as a metacognitivist. Scandinavian Journal of Educational Research, 35(4), 305-320. https://doi.org/10.1080/0031383910350406

Brookhart, S. M. (2011). Educational assessment knowledge and skills for teachers. Educational Measurement: Issues and Practice, 30(1), 3-12. https://doi.org/10.1111/j.1745-3992.2010.00195.x

Brown, A. (1987). Metacognition, executive control, self-regulation, and other more mysterious mechanisms. In F. E. Weinert, \& R. H. Kluwe (Eds.), Metacognition, motivation, and understanding (pp. 65-116). Hillsdale, NJ: Lawrence Erlbaum, Publishers.

Brown, A. L. (1978). Knowing when, where, and how to remember: A problem of metacognition. In R. Glaser (Ed.), Advances in instructional psychology (Vol. 1., pp. 77-165). Hillsdale, NJ: Erlbaum Associates.

Brown, A. L., Bransford, J. D., Ferrara, R. A., \& Campione, J. C. (1983). Learning, remembering, and understanding. In P. H. Mussen (Ed.), Handbook of child psychology (4th ed.) Cognitive development (Vol. 3, pp. 77- 166). New York: Wiley.

Byrne, B. (2012). Structural Equation Modeling With Mplus. Basic Concepts, Applications, and Programming (Taylor \& Francis, Routledge).

Chan, K. W. (2001, December). Validation of a measure of personal theories about teaching and learning. Paper presented in the AARE 2001 Conference held at Fremantle, Perth, Australia.

Cronbach, L. (1951). Coefficient alpha and the internal structure of tests. Psychometrika, 16, 297-334. https://doi.org/10.1007/BF02310555

Dinsmore, D. L., Alexander, P. A., \& Loughlin, S. M. (2008). Focusing the conceptual lens on metacognition, self-regulation, and self-regulated learning. Educational Psychology Review, 20(4), 391-409. https://doi.org/10.1007/s10648-008-9083-6

Entwistle, N. J., \& Ramsden, P. (1983). Understanding student learning. London: Croom Helm.

Favieri, A. G. (2013). General Metacognitive Strategies Inventory (GMSI) and the Metacognitive Integrals Strategies Inventory (MISI). Electronic Journal of Research in Educational Psychology, 11(3), 831-850. https://doi.org/10.14204/ejrep.31.13067

Flavell, J. H. (1976). Metacognitive aspects of problem solving. The Nature of Intelligence, 12, 231-235.

Flavell, J. H. (1977). Cognitive development. Prentice-Hall, Inc., Englewood Cliffs, New Jersey. 
Geisinger, K. F. (2016). Intended and unintended meanings of validity: Some clarifying comments. Assessment in Education: Principles, Policy \& Practice, 23(2), 287-289. https://doi.org/10.1080/0969594X.2016.1158150

Ghonsooly, B., Khajavy, G. H., \& Mahjoobi, F. M. (2014). Self-efficacy and metacognition as predictors of Iranian teacher trainees' academic performance: A path analysis approach. Procedia-Social and Behavioral Sciences, 98, 590-598. https://doi.org/10.1016/j.sbspro.2014.03.455

Gliner, J., Morgan, G., \& Harmon, R. (2001) Measurement reliability. Journal of the American Academy of Child and Adolescent Psychiatry, 40(4), 486-488. https://doi.org/10.1097/00004583-200104000-00019

Goldstein, H. (2015). Validity, science and educational measurement. Assessment in Education: Principles, Policy \& Practice, 22(2), 193-201. https://doi.org/10.1080/0969594X.2015.1015402

Greene, J. A., Costa, L.-J., \& Dellinger, K. (2011). Analysis of Self-Regulated Learning processing using statistical models for count data. Metacognition Learning, 6, 275-301. https://doi.org/10.1007/s11409-011-9078-4

Hacker, D. J., Dunlosky, J., \& Graesser, A. C. (Eds.). (2009). Handbook of metacognition in education. Routledge.

Hair, J., Black, W., Babin, B., \& Anderson, R. (2010). Multivariate data analysis (6th ed.). Pearson Education, Upper Saddle River.

Hakkarainen, K., Lonka, K., \& Lipponen, L. (1999). Tutkiva oppiminen. Porvoo, WSOY.

Hoe, S. (2008). Issues and Procedures in Adapting Structural Equation Modeling Technique. Quantitative Methods Inquires. Journal of Applied Quantitative Methods, 3(1), 76-83.

Hopfenbeck, T. N. (2009). Learning about Students' Learning Strategies. An empirical and theoretical investigation of self-regulation and learning strategy questionnaires in PISA.

Hoyle, R. (1995). The structural equation modeling approach: Basic concepts and fundamental issues. In R. Hoyle (Ed.), Structural Equation Modeling: Concepts, Issues, and Applications (pp. 1-15) (Thousand Oaks, Sage).

Hu, L., \& Bentler, P. M. (1999). Cut-off criteria for fit indexes in covariance structure analysis: Conventional criteria versus new alternatives. Structural Equation Modeling, 6(1), 1-55. https://doi.org/10.1080/10705519909540118

Jacobs, J. E., \& Paris, S. G. (1987). Children's metacognition about reading: Issues in definition, measurement, and instruction. Educational $\quad$ Psychologist, 22(3-4), https://doi.org/10.1080/00461520.1987.9653052

Jiang, Y., Ma, L., \& Gao, L. (2016). Assessing teachers' metacognition in teaching: The Teacher Metacognition Inventory. Teaching and Teacher Education, 59, 403-413. https://doi.org/10.1016/j.tate.2016.07.014

Jöreskog, K. (1969). A general approach to confirmatory maximum likelihood factor analysis. Psychometrika, 34, 183-202. https://doi.org/10.1007/BF02289343

Kline, R. (2011). Principles and Practice of Structural Equation Modeling (3rd ed.). New York \& London: The Guilford Press.

Lai, E. R. (2011). Metacognition: A literature review. Always learning: Pearson research report.

Livingston, J. A. (1997). Metacognition: An overview. Retrieved from http://www.gse.buffalo.edu/fas/shuell/cep564/Metacog.htm

MacCallum, R., \& Austin, J. (2000). Applications of structural equation modelling in psychological research. Annual Reviews of Psychology, 51, 201-226. https://doi.org/10.1146/annurev.psych.51.1.201

Mai, M. Y. (2015). Science Teachers Self Perception about Metacognition. Journal of Educational and Social Research, 5(1S1), 77. https://doi.org/10.5901/jesr.2015.v5n1s1p77

Martinez, S., \& Davalos, D. (2016). Investigating metacognition, cognition, and behavioral deficits of college students with acute traumatic brain injuries. Journal of American College Health, 1-7. https://doi.org/10.1080/07448481.2016.1167057

Marton, F., \& Booth, S. A. (1997). Learning and awareness. Psychology Press. 
McDonald, R., \& Ho, R. (2002). Principles and Practises in Reporting Structural Equation Analyses. Psychological Methods, 7, 64-82. https://doi.org/10.1037/1082-989X.7.1.64

McGrath, R. E. (2005). Conceptual complexity and construct validity. Journal of Personality Assessment, 85(2), 112-124. https://doi.org/10.1207/s15327752jpa8502_02

Ministry of Education and Culture Finland. (2015). Finnish VET in a nutshell. National Board of Education, Centre for International Mobility (CIMO).

Ormrod, J. E. (2004). Human Learning. Upper Saddle River, NJ: Pearson Prentice Hall.

Pintrich, P. R. (2000). The role of goal orientation in self-regulated learning. In M. Boekaerts, P. Pintrich, \& M. Zeidner (Eds.), Handbook of self-regulation (pp. 451-502). San Diego: Academic. https://doi.org/10.1016/B978-012109890-2/50043-3

Pintrich, P. R., Smith, D. A., Garcia, T., \& McKeachie, W. J. (1993). Reliability and predictive validity of the Motivated Strategies for Learning Questionnaire (MSLQ). Educational and Psychological Measurement, 53, 801-813. https://doi.org/10.1177/0013164493053003024

Schoenfeld, A. H. (1987). What's all the fuss about metacognitive? In A. H. Schoenfeld (Ed.), Cognitive science and mathematics education. NJ, LEA.

Schraw, G., \& Dennison, R. S. (1994). Assessing Metacognitive Awareness. Contemporary Educational Psychology, 19, 460-475. https://doi.org/10.1006/ceps.1994.1033

Schraw, G., \& Moshman, D. (1995). Metacognitive theories. Educational Psychology Review, 7(4), 351-371. https://doi.org/10.1007/BF02212307

Schraw, G., Crippen, K. J., \& Hartley, K. (2006). Promoting self-regulation in science education: Metacognition as part of a broader perspective on learning. Research in Science Education, 36(1-2), 111-139. https://doi.org/10.1007/s11165-005-3917-8

Seraphin, K. D., Philippoff, J., Kaupp, L., \& Vallin, L. M. (2012). Metacognition as Means to Increase the Effectiveness of Inquiry-Based Science Education. Science Education International, 23(4), 366-382.

Stefanou, C. R., Perencevich, K. C., DiCintio, M., \& Turner. J. C. (2004). Supporting Autonomy in the Classroom: Ways Teachers Engourage Student Decision Making and Ownership. Educational Psychologist, 39(2), 97-110. https://doi.org/10.1207/s15326985ep3902_2

Steiger, J. (1990). Structural model assessment and modification: An interval estimation approach. Multivariate Behaviour Research, 25, 173-180. https://doi.org/10.1207/s15327906mbr2502_4

Steiger, J. (2000). Point estimation, hypothesis testing, and interval estimation using the RMSEA: Some comments and a reply to Hayduk and Glaser. Structural Equation Modeling, 7(2), 149-162. https://doi.org/10.1207/S15328007SEM0702_1

Tanner, K. D. (2012). Promoting student metacognition. CBE-Life Sciences Education, 11(2), 113-120. https://doi.org/10.1187/cbe.12-03-0033

Teo, T. K. G., \& Chai, C. S. (2008). Confirmatory factor analysis of the Conception for Teaching and Learning Questionnaire (CTLQ).

Thompson, V. A., \& Johnson, S. C. (2014). Conflict, metacognition, and analytic thinking. Thinking \& Reasoning, 20(2), 215-244. https://doi.org/10.1080/13546783.2013.869763

Tucker, L., \& Lewis, C. (1973). A reliability coefficient for maximum likelihood factor analysis. Psychometrika, 38, 1-10. https://doi.org/10.1007/BF02291170

Ullman, J. (2001). Structural equation modelling. In B. Tabachnik, \& L. Fidell (Eds.), Using Multivariate Statistics (4th ed., pp. 653-771). Allyn \& Bacon, Needham Heights.

Vermunt, J. D., \& Verloop, N. (1999). Congruence and friction between learning and teaching. Learning and Instruction, 9, 257-264. https://doi.org/10.1016/S0959-4752(98)00028-0

Virta, K. (2005). Kindergarten, sloyd and classroom teacher trainees' self-directed learning, Metacognitive Regulation and web-based support. Annales Universitatis Turkuensis.

von Wright, J. (1992). Reflections on reflection. Learning and Instruction, 2, 59-68. https://doi.org/10.1016/0959-4752(92)90005-7 
Weinstein, C. E., Zimmerman, S. A., \& Palmer, D. R. (1988). Assessing learning strategies: The design and development of the LASSI. In C. E. Weinstein, E. T. Goetz, \& P. A. Alexander (Eds.), Learning and study strategies: Issues in assessment, instruction, and evaluation (pp. 25-40). San Diego: Academic Press. https://doi.org/10.1016/B978-0-12-742460-6.50009-8

Wenden, A. (1991). Learning strategies for learner autonomy: Planning and implementing learner training for language learners. Hemel Hemstead, Hertfordshire: Prentice Hall.

West, S., Taylor, A., \& Wu, W. (2012). Model Fit and Model Selection in Structural Equation Modeling. In R. Hoyle (Ed.), Handbook of Structural Equation Modeling (pp. 209-231). The Guilford Press.

Whitebread, D., Coltman, P., Pasternak, D. P., Sangster, C., Grau, V., Bingham, S., ... Demetriou, D. (2009). The development of two observational tools for assessing metacognition and Self-Regulated Learning in young children. Metacognition and Learning, 4(1), 63-85. https://doi.org/10.1007/s11409-008-9033-1

Wilkins, S. (1996). Fostering independence with metacognition. In Proceedings of Autonlomy 2000: The development of learning independence in language learning (pp. 254-263).

Winne, P. H., \& Jamieson-Noel, D. (2002). Exploring students' calibration of self reports about study tactics and $\begin{array}{lllll}\text { achievement. Contemporary } & \text { Educational }\end{array}$ https://doi.org/10.1016/S0361-476X(02)00006-1

Winne, P., \& Hadwin, A. (2008). The weave of motivation and self-regulated learning. In D. Schunk, \& B. Zimmerman (Eds.), Motivation and self-regulated learning: Theory, research, and applications (pp. 297-314). Mahwah: Erlbaum.

Woolfolk, A. E., \& Hoy, W. K. (1990). Prospective teachers' sense of efficacy and beliefs about control. Journal of Educational Psychology, 82(1), 81. https://doi.org/10.1037/0022-0663.82.1.81

Young, A., \& Fry, J. D. (2008). Metacognitive Awareness and academic achievement in college students. Journal of the Scholarship of Teaching and Learning, 8(2), 1-10.

Zimmerman, B. J. (2000). Attaining self-regulation: A social cognitive perspective. In M. Boekaerts, P. Pintrich, \& M. Zeidner (Eds.), Handbook of Self-regulation. Academic Press, USA. https://doi.org/10.1016/b978-012109890-2/50031-7

Zimmerman, B. J., \& Martinez-Pons, M. (1986). Development of a structured interview for assessing student use of Self-Regulated Learning strategies. American Educational Research Journal, 23, 614-628. https://doi.org/10.3102/00028312023004614

Zimmerman, B. J., \& Schunk, D. H. (Eds.). (2011). Handbook of self-regulation of learning and performance. Taylor \& Francis.

\section{Appendix 1}

MAIT-18 Correlation matrix

\begin{tabular}{|c|c|c|c|c|c|c|c|c|c|c|c|c|c|c|c|c|c|c|}
\hline & 1 & 2 & 4 & 6 & 7 & 8 & 9 & 10 & 11 & 13 & 14 & 16 & 17 & 18 & 19 & 21 & 22 & 24 \\
\hline 1 & & & & & & & & & & & & & & & & & & \\
\hline 2 & .37 & & & & & & & & & & & & & & & & & \\
\hline 4 & .33 & .40 & & & & & & & & & & & & & & & & \\
\hline 6 & .44 & .40 & .42 & & & & & & & & & & & & & & & \\
\hline 7 & .42 & .44 & .43 & .51 & & & & & & & & & & & & & & \\
\hline 8 & .22 & .29 & .26 & .32 & .29 & & & & & & & & & & & & & \\
\hline 9 & .25 & .32 & $\mathrm{~ns}$ & ns & .25 & .14 & & & & & & & & & & & & \\
\hline 10 & .19 & .40 & .41 & .34 & .41 & .21 & .22 & & & & & & & & & & & \\
\hline 11 & .26 & .22 & .19 & .37 & .40 & .17 & .36 & .28 & & & & & & & & & & \\
\hline 13 & .32 & .17 & .32 & .38 & .39 & .18 & ns & .30 & .36 & & & & & & & & & \\
\hline 14 & .31 & .32 & .33 & .29 & .43 & ns & .14 & .39 & .27 & .33 & & & & & & & & \\
\hline 16 & .36 & .25 & .34 & .44 & .44 & .15 & ns & .32 & .26 & .56 & .53 & & & & & & & \\
\hline
\end{tabular}




\begin{tabular}{lllllllllllllllllll}
\hline 17 & .22 & .24 & .26 & .44 & .39 & $\mathrm{~ns}$ & .14 & .30 & .40 & .34 & .48 & .38 & & & & \\
18 & .24 & .20 & $\mathrm{~ns}$ & .38 & .35 & $\mathrm{~ns}$ & .37 & .35 & .48 & .31 & .35 & .35 & .51 & & & \\
19 & .33 & .28 & .35 & .36 & .45 & .17 & .18 & .34 & .39 & .33 & .35 & .27 & .44 & .39 & & \\
21 & .27 & .28 & .36 & .45 & .40 & $\mathrm{~ns}$ & .16 & .39 & .29 & .39 & .53 & .50 & .58 & .42 & .44 & & \\
22 & .19 & .24 & .18 & .37 & .44 & .14 & .23 & .37 & .31 & .31 & .35 & .36 & .49 & .48 & .36 & .46 & \\
24 & .21 & .19 & .20 & .31 & .36 & $\mathrm{~ns}$ & .22 & .35 & .31 & .35 & .34 & .34 & .42 & .45 & .29 & .49 & .60 \\
\hline
\end{tabular}

PEARSON'S CORRELATIONS.

ns. $=$ NON-SIGNIFICANT CORRELATION $(\mathrm{p}>.05)$.

\section{Copyrights}

Copyright for this article is retained by the author(s), with first publication rights granted to the journal.

This is an open-access article distributed under the terms and conditions of the Creative Commons Attribution license (http://creativecommons.org/licenses/by/4.0/). 